\title{
HTLV-I associated arthritis: characteristics of an HTLV-I virus infected $T$ cell line from synovial fluid
}

Katsumi Eguchi, Tatsufumi Nakamura, Masanobu Mine, Hiroaki Ida, Atsushi Kawakami, Kiyoshi Migita, Kunihiko Nagasato, Akihiko Kurata, Takaaki Fukuda, Shigenobu Nagataki

\begin{abstract}
$A \quad T$ cell line from mononuclear cells in the synovial fluid of a patient with polyarthritis was established. The $\mathbf{T}$ cell line reacted with serum samples positive for antibodies to human $T$ cell lymphotropic virus type $I$ (HTLV-I) and with monoclonal antibody to HTLV-I p19. In Southern blotting with an env-pX-LTR HTLV-I probe and digestion of $T$ cell line DNA with the restriction enzymes ClaI, DraI, and PstI generated fragments that were identical to those found in two HTLV-I infected $T$ cell lines established from adult $T$ cell leukaemia or HTLV-I associated myelopathy. The $T$ cell line expressed CD2, CD3, CD4, CD45RA, CD29, HLA-DR, CD25, and CD26 antigens, but not CD8 and CD20 antigens. Large amounts of interleukin 6, interferon $\gamma$, and tumour necrosis factor $\alpha$ were secreted in the culture supernatants of this cell line. This line helped immunoglobulin production by B cells, but not K562, Raji, and synovial cell lysis.
\end{abstract}

Human $T$ cell lymphotropic virus type I (HTLV-I) is closely associated with human adult $\mathrm{T}$ cell leukaemia ${ }^{1}$ and HTLV-I associated myelopathy. ${ }^{2}$ Infection with HTLV-I has recently been described in association with a number of rheumatic syndromes, including polyarthritis with some features resembling rheumatoid arthritis ${ }^{34}$ and polymyositis. ${ }^{5}$

We here describe the case of a patient infected with HTLV-I, which was complicated by acute polyarthritis mimicking rheumatoid arthritis. To verify whether the retrovirus at the inflammatory site of the synovium from the patient is identical to that of the HTLV-I strain found in adult $T$ cell leukaemia or HTLV-I associated myelopathy we isolated a virus developed from an interleukin 2 dependent $T$ cell line established from mononuclear cells in synovial fluid from the patient. We also investigated the phenotypic characteristics and immunological functions of an HTLV-I infected $T$ cell line.

\section{Case report}

A 68 year old Japanese woman was admitted to our hospital in March 1989 because of symmetric polyarthritis associated with morning stiffness.
She reported the abrupt onset of right shoulder joint pain one month before admission. She was born in an HTLV-I endemic area in south western Japan, and had never had a blood transfusion.

Physical examination on admission disclosed several warm and tender joints, with symmetric distribution (shoulder, wrist, hip, and knee joints). Neither lymphadenopathy nor abnormal neurological findings were present.

Laboratory studies showed that erythrocyte sedimentation rate $(136 \mathrm{~mm} / \mathrm{h}), \mathrm{C}$ reactive protein $(88.3 \mathrm{mg} / \mathrm{l})$, serum fibrinogen $(5.63 \mathrm{~g} / \mathrm{l})$, and $\alpha_{2}$ globulin (16.8\%) were all raised. The white blood cell count was $6.5 \times 10^{9} / 1$ and consisted of $73 \%$ polymorphonuclear cells, $22 \%$ lymphocytes, $3 \%$ monocytes, and $2 \%$ basophils. Circulating CD3 + cells (63.2\%), CD4+ cells (41.8\%), CD8 + cells $(23 \cdot 5 \%)$, and CD20 + cells $(12 \cdot 4 \%)$ were all within the normal ranges. Results of protein electrophoresis were normal, except for increased polyclonal IgA $(6.8 \mathrm{~g} / \mathrm{l})$. Rheumatoid factor and antinuclear antibodies were negative. Radiographic examination of the hands and knees showed no bone abnormalities, whereas bone scintigraphy showed symmetric hot uptake in the joints of the shoulders, wrists, and knees. Antibody to HTLV-I was positive in serum and synovial fluid by the particle agglutination test (1/2048 positive); this was confirmed by western blotting. An enzyme linked immunosorbent assay (ELISA) showed that antibodies to HIV were absent. The synovial fluid leucocyte count was increased $\left(11 \times 10^{9} / 1\right)$ and included $58 \%$ mononuclear cells. The mononuclear cells comprised CD3 + cells $(69 \%)$, CD4+ cells (61\%), CD4+CD45RA + cells $(5 \cdot 7 \%)$, and CD8+ cells (12.0\%). CD20+ cells were increased at $22.5 \%$. As rheumatoid arthritis was suspected she was treated with sulindac. Twelve months later the joints affected by active disease had been reduced to two and her overall condition was good.

\section{Methods}

ESTABLISHMENT OF THE CELL LINE

Mononuclear cells were isolated from the patient's synovial fluid by Ficoll-Conray density gradient centrifugation. ${ }^{6}$ These cells were depleted of adherent cells by incubating the cell suspensions in Petri dishes for two hours at $37^{\circ} \mathrm{C}$. T cell enriched populations were pre- 
pared from the non-adherent cells by rosetting with sheep red blood cells and passage through a nylon wool column at $37^{\circ} \mathrm{C}$ for one hour. The $\mathrm{T}$ cells were suspended in RPMI 1640 medium supplemented with $20 \%$ fetal bovine serum, 100 $\mathrm{U} / \mathrm{ml}$ interleukin 2 (IL-2) and $2 \mathrm{mM} \mathrm{L}$ glutamine, then seeded at a density of $6 \times 10^{4}$ cells $/ \mathrm{ml}$ in a 48 well plastic tray. The growth medium was changed every four days. The continuous cell line that was established two months later, called HAAP-1, was maintained in culture IL- 2 in the absence of feeder cells for six months.

\section{SOUTHERN BLOT ANALYSIS}

The proviral sequences integrated in the $T$ cell line DNA were analysed by Southern blot analysis. ${ }^{7}$ The cellular DNA extracted from the cells was digested with restriction endonuclease (EcoRI, ClaI, DraI, and PstI), then fractionated according to size by agarose gel electrophoresis and transferred to a nitrocellulose membrane, which was then hybridised with DNA labelled with ${ }^{32} \mathrm{P}$ containing env-pX-LTR of HTLV-I sequences for 18 hours at $65^{\circ} \mathrm{C}$. After hybridisation the filter was washed and exposed to $x$ ray film.

DUAL IMMUNOFLUORESCENT ANALYSIS

Dual immunofluorescent analysis was carried out as described in detail previously. ${ }^{6}$ Briefly, the cells were exposed to a fluorescein isothiocyanate conjugated monoclonal antibody and a phycoerythrin (PE)-conjugated monoclonal antibody for one hour at $4^{\circ} \mathrm{C}$. When the cells had been washed the percentages of positive cells were determined by flow microfluorimetry (EPICS C cell sorter; Coulter Electronicus, Hialeah, FL, USA).

\section{CYTOKINE MEASUREMENT}

All cytokine measurements were performed in duplicate.

Interleukin $1 \beta$ (IL-1 $\beta$ ) was measured by immunoradiometric assay (Medgenix, Fleurus, Belgium). Tubes precoated with monoclonal antibody to human IL-1 $\beta$ were incubated with $200 \mu \mathrm{l}$ samples and ${ }^{125} \mathrm{I}$ labelled monoclonal antibody to IL-1 $\beta$ overnight at room temperature. After washing, radioactivity in the assay tubes was counted by a gamma scintillation counter. The sensitivity of the IL-1 $\beta$ determination was $5 \mathrm{pg} / \mathrm{ml}$.

Interferon $\gamma$ (IFN- $\gamma$ ) was measured by immunoradiometric assay (Sucrosep IFN- $\gamma$ IRMA kit; Boots Celltech Diagnostics, Berkshire, United Kingdom). Samples were reacted with $50 \mu \mathrm{l}$ monoclonal antibody to ${ }^{125}$ I labelled IFN- $\gamma$ for two hours at room temperature. Prewashed buffer and Sucrosep separation reagent were added and the tubes allowed to stand for 15 minutes. After aspiration, radioactivity was counted by a gamma scintillation counter. The sensitivity of the IFN- $\gamma$ determination was $1 \mathrm{U} / \mathrm{ml}$.

Tumour necrosis factor $\alpha$ (TNF- $\alpha$ ) was measured by an ELISA (SRL Laboratory, Tokyo, Japan). Plates precoated with monoclonal antibody to human TNF- $\alpha$ were incubated with samples, followed by further incu- bation with polyclonal rabbit anti-TNF- $\alpha$ and goat antirabbit IgG conjugated to horseradish peroxidase. Excess reactants were removed by washing three times between each step with $0.01 \mathrm{M}$ phosphate buffer ( $\mathrm{pH} 7 \cdot 4$ ) containing $1 \%$ bovine serum albumin. Addition of enzyme substrate produced a chromogenic product, whose absorption was measured at $490 \mathrm{~nm}$. Assay sensitivity was $20 \mathrm{pg} / \mathrm{ml}$.

Interleukin 6 (IL-6) activity was measured with a murine IL- 6 dependent cell line MH60.BSF-2 described by Matsuda et al. ${ }^{8}$ MH60.BSF- 2 cells $\left(10^{4}\right.$ cells/well) were cultured in RPMI 1640 medium containing $1 \%$ fetal bovine serum, $5 \times 10^{-5} \mathrm{M}$ 2-mercaptoethanol, and antibiotics in a $200 \mu \mathrm{l}$ well of a 96 well flat bottomed microtitre plate. After 72 hours' incubation the viable cell number was measured by improved colorimetric assay with MTT [3-(4,5-dimethylthiazoyl-2-yl)-2,5-diphenytetrazolium bromide] (Sigma, St Louis, MO, USA). Samples were titrated in twofold dilutions using recombinant IL-6 obtained from Genzyme as a reference standard. In this assay, half maximum proliferation is induced by $0 \cdot 1 \mathrm{U} / \mathrm{ml}$ IL-6.

\section{CYTOTOXICITY ASSAY}

Cytotoxicity was measured by a four hour ${ }^{51} \mathrm{Cr}$ release assay. K562, Raji, and synovial cells, which were used as the target cells, were radiolabelled with $\mathrm{Na}_{2}{ }^{51} \mathrm{CrO}_{4}$ at $37^{\circ} \mathrm{C}$ for one hour. Graded numbers of effector cells were added to the target cells at ratios of 160:1, 80:1, and 40:1.

DETECTION OF HELPER AND SUPPRESSOR T CELL FUNCTION

The functions of helper and suppressor $T$ cells were determined by a reconstituted cell mixing method. ${ }^{9} \mathrm{~T}$ cell subsets were separated from the peripheral blood of the patient by a panning method using monoclonal antibodies to CD4 and CD8. In the experiments on helper $T$ cells a mixture of $B$ cells and macrophages was cultured with autologous CD4+ or HAAP-1 cells in the presence or absence of pokeweed mitogen. To study suppressor-inducer $T$ cells a mixture of $B$ cells, macrophages, and CD8 + cells was cultured with autologous CD4+ or HAAP-1 cells in the presence of pokeweed mitogen. To test the suppressor-effector $\mathrm{T}$ cell function a mixture of $B$ cells, macrophages, and CD4+ cells was incubated with CD8+ or HAAP-1 cells with pokeweed mitogen. IgG concentrations in the supernatants were determined by a solid phase radioimmunoassay. 9

\section{Results}

The T cell line, designated HAAP-1 cells, reacted with autologous serum, with serum samples from patients with adult $T$ cell leukaemia and HTLV-I associated myelopathy, and with monoclonal antibody to HTLV-I p19, but not with serum samples from normal subjects in the absence of antibody to HTLV-I in an indirect immunofluorescent assay.

In the Southern blotting experiment with the ${ }^{32} \mathrm{P}$ labelled env-pX-LTR of the HTLV-I probe, $E$ coRI had no cleavage sites within the HTLV-I 
A

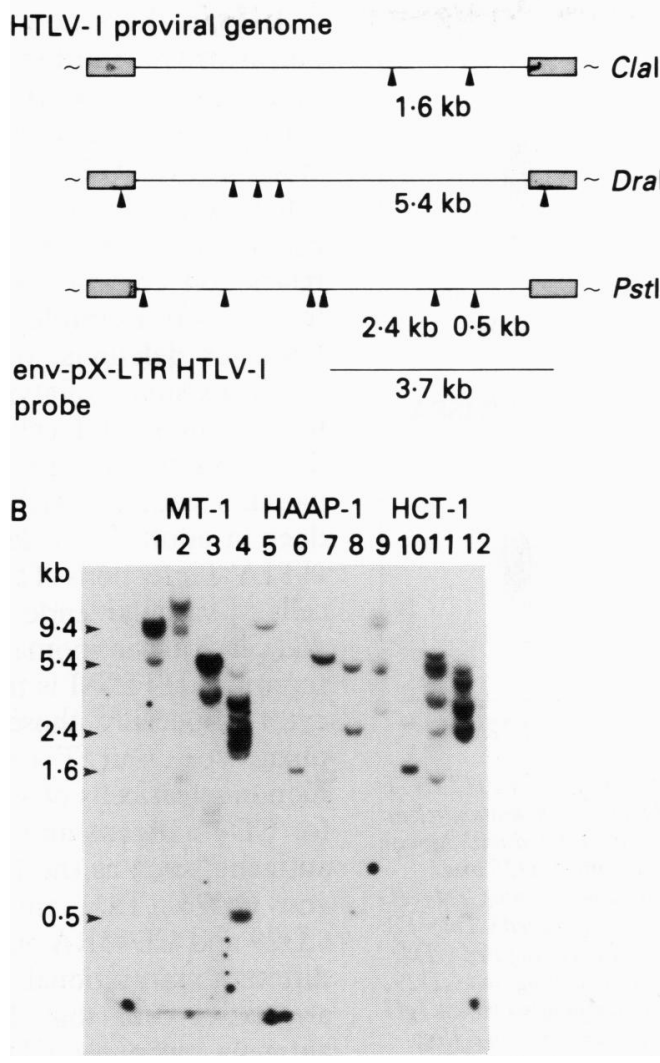

Figure 1 (A) Horizontal lines represent the HTLV-I proviral genome. Vertical arrowheads indicate the cleavage sites of ClaI, DraI, and PstI. (B) Southern blot analysis of the provirus DNA integrated in cell line HAAP-I. Total genomic DNA $(10 \mu \mathrm{g})$ from a human adult $T$ cell leukaemia cell line (MT-1, lanes 1 to 4), HAAP-1 cell line (lanes 5 to 8), and an HCT-1 cell line (lanes 9-12) was digested with EcoRI (lanes 1, 5, and 9), ClaI (lanes 2, 6, and 10), DraI (lanes 3, 7, and 11), and PstI (lanes 4, 8, and 12) then size fractionated by electrophoresis on agarose gels and transferred to a nitrocellulose membrane. The probe was cloned HTLVI DNA covering the env-pX-LTR viral genome. The size markers (left) represent the HindIII digest of DNA. $k b=$ kilobase. genome, whereas ClaI, DraI, and PstI had several (fig 1A). As controls, an HTLV-I infected T cell line (MT-1) established from a patient with adult $T$ cell leukaemia and an HTLV-I infected $T$ cell line (HCT-1) from mononuclear cells in the cerebrospinal fluid of a patient with HTLV-I associated myelopathy ${ }^{7}$ were used. The EcoRI digests of HAAP-1 DNA gave broad bands larger than 9 kilobases $(\mathbf{k b})$ (fig 1), which are the genomic size of HTLV-I, indicating that multiple copies of the provirus were integrated in HAAP-1 DNA. Digestion of HAAP-1 DNA with the ClaI generated a $1.6 \mathrm{~kb}$ fragment that was identical to the fragments in MT-1 and HCT-1 DNA. Digestion of the HAAP-1 DNA with DraI generated a $5.4 \mathrm{~kb}$ fragment that was identical to the fragments in MT-1 and HCT-1. This band represented the internal fragment of HTLV-I (restriction map). PstI cleaved the HTLV-I genome at five sites and generated two fragments: 2.4 and $0.5 \mathrm{~kb}$. Two bands, corresponding exactly to these sites, were detected as major bands in the HAAP-1 DNA after PstI digestion, evidence that in the HAAP-I provirus the PstI sites are the same as those in the HTLV-I found in adult T cell leukaemia and HTLV-I associated myelopathy.

Next, we examined the phenotypic characteristics of the HAAP-1 cells using the monoclonal antibodies. The $\mathrm{T}$ cell line was positive for the CD2, CD3, CD4, HAL-DR, CD25, and CD26 antigens, but negative for the CD8 and CD20 antigens. The data indicate that the line has the phenotype of activated or memory CD4+ cells. Both the CD29 and CD45RA antigens were expressed on the cell surface of the $T$ cell line (fig 2).

To discover whether the $T$ cell line could produce cytokines the presence of the cytokines IL-1 $\beta$, IL-6, IFN- $\gamma$, and TNF- $\alpha$ was determined in the culture supernatants. The $\mathrm{T}$ cell

$T$ cell line function in immunoglobulin production

\begin{tabular}{|c|c|c|c|}
\hline Mixture & Added cells & $P W M^{*}$ & 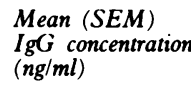 \\
\hline $\begin{array}{l}\text { Helper } T \text { cell function } \\
\mathrm{B}^{*}\left(5 \times 10^{4}\right)+\mathrm{M}^{*}\left(5 \times 10^{3}\right)\end{array}$ & $\begin{array}{l}0 \\
\text { CD4+ cells }\left(2 \times 10^{+}\right) \\
\text {CD4+ cells }\left(4 \times 10^{+}\right) \\
\text {HAAP-1 }\left(2 \times 10^{+}\right) \\
\text {HAAP-1 }\left(4 \times 10^{+}\right) \\
0 \\
\text { CD4+ cells }\left(2 \times 10^{+}\right) \\
\text {CD4+ cells }\left(4 \times 10^{+}\right) \\
\text {HAAP-1 }\left(2 \times 10^{+}\right) \\
\text {HAAP-1 }\left(4 \times 10^{+}\right)\end{array}$ & $\begin{array}{l}(+) \\
(+) \\
(+) \\
(+) \\
(+) \\
(-) \\
(-) \\
(-) \\
(-) \\
(-)\end{array}$ & $\begin{array}{r}50(15) \\
2040(180) \\
3450(240) \\
400(80) \\
1080(120) \\
38(20) \\
45(30) \\
43(20) \\
180(40) \\
240(70)\end{array}$ \\
\hline $\begin{array}{l}\text { Suppressor-inducer cell function } \\
\text { B }\left(5 \times 10^{+}\right)+M \emptyset\left(5 \times 10^{3}\right)+\mathrm{CD} 4+\left(2 \times 10^{+}\right) \\
\text {B }\left(5 \times 10^{+}\right)+M ø\left(5 \times 10^{3}\right)+\text { HAAP-1 }\left(2 \times 10^{+}\right)\end{array}$ & 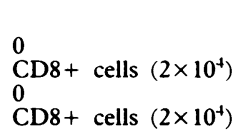 & $\begin{array}{l}(+) \\
(+) \\
(+) \\
(+)\end{array}$ & $\begin{array}{r}1540(140) \\
620(80) \\
580(120) \\
660(100)\end{array}$ \\
\hline $\begin{array}{l}\text { Suppressor-effector cell function } \\
\mathbf{B}\left(5 \times 10^{+}\right)+M ø\left(5 \times 10^{3}\right)+C D 4+\left(2 \times 10^{4}\right)\end{array}$ & $\begin{array}{l}0 \\
\text { CD8+ cells }\left(2 \times 10^{+}\right) \\
\text {CD8+ cells }\left(4 \times 10^{+}\right) \\
\text {HAAP-1 }\left(2 \times 10^{+}\right) \\
\text {HAAP-1 }\left(4 \times 10^{+}\right)\end{array}$ & $\begin{array}{l}(+) \\
(+) \\
(+) \\
(+) \\
(+)\end{array}$ & $\begin{array}{r}1350(100) \\
580(60) \\
320(50) \\
1850(90) \\
2640(110)\end{array}$ \\
\hline
\end{tabular}


A

CD4-CD25

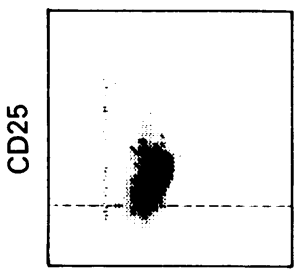

CD4

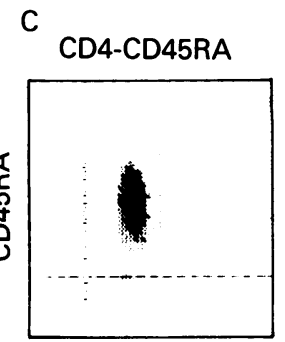

CD4
B

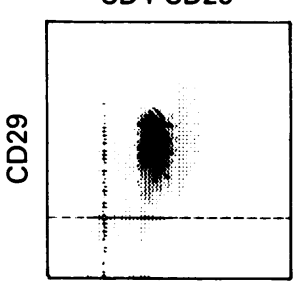

CD4

D

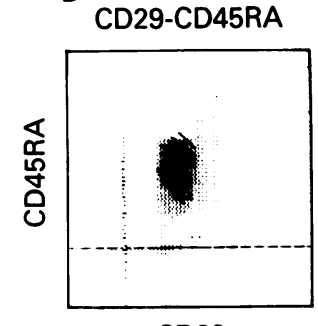

CD29

Figure 2 Dual immunofluorescent analysis of the HTLV-I infected $T$ cell line $(H A A P-1)$ established from mononuclear cells of synovial fluid. The cells were first treated with human IgG then stained. $(A)(P E)$ conjugated anti-CD25 and

fluorescein isothiocyanate (FITC) conjugated anti-CD4; (B) $P E$ conjugated anti-CD29 and FITC conjugated CD4;(C) $P E$ conjugated anti-CD45RA and FITC conjugated CD4;

(D) PE conjugated CD45RA and FITC conjugated CD29.

$P E$ conjugated mouse IgG and FITC conjugated mouse IgG were used as the controls. Samples were analysed in a flow cytometer gated to exclude non-viable cells. Results are

presented as 'density' plots. The $x$ axis shows green

fluorescence, the y axis red fluorescence.

line secreted large amounts of IL-6 (191 (SEM $5 \cdot 1) \mathrm{U} / \mathrm{ml}), \mathrm{IFN}-\gamma(340 \mathrm{U} / \mathrm{ml})$, and TNF- $\alpha$ (66 $\mathrm{pg} / \mathrm{ml})$, but not IL-1 $\beta$.

To determine whether this cell line has natural killer or IL-2 activated killer cell activity we studied its killer cell activity toward K562, Raji, and synovial cells. Killer cells activated by IL-2 used as control effector cells were able to lyse these target cells, whereas HAAP-1 cells could not.

Finally, to investigate the helper $T$ cell function we cultured varying numbers of the $T$ cells with a reconstituted mixture of $B$ cells and macrophages in the presence or absence of pokeweed mitogen (table). The concentration of IgG in the culture supernatant increased with an increase in the numbers of HAAP-1 cells. Increased IgG production by the mixture of $B$ cells and $T$ cells was found in the culture supernatants in the presence or absence of pokeweed mitogen. As a control, autologous CD4+ cells also enhanced the IgG production significantly, whereas HAAP-1 cells had no suppressor-inducer or suppressor-effector $\mathrm{T}$ cell functions.

\section{Discussion}

Patients with adult $T$ cell leukaemia who presented with proliferative synovitis have recently been reported. ${ }^{10}$ Rheumatic manifestations complicated with HTLV-I associated myelopathy have also been recognised, ${ }^{11}$ and it is increasingly suspected that such rheumatic manifestations may be associated with HTLV-I infection. ${ }^{34}$ We therefore established an

HTLV-I infected $T$ cell line from mononuclear cells from the synovial fluid of a patient with polyarthritis. Southern blot hybridisation with four restriction enzymes showed that the virus isolated from the $T$ cell line was indistinguishable from the HTLV-I in patients with adult T cell leukaemia and HTLV-I associated myelopathy. Although the restriction sites of the four restriction enzymes were identical, minor differenes-for example, base substitutions, insertions, or deletions, may exist.

The existence of atypical lymphocytes similar to those in adult $\mathrm{T}$ cell leukaemia from synovial fluid and tissue suggests that the HTLV-I in patients with polyarthritis affects $T$ cells as it does in adult $\mathrm{T}$ cell leukaemia. ${ }^{3}{ }^{411}$ Although HTLV-I infections of human osteogenic sarcoma cells, ${ }^{12}$ vascular endothelial cells, ${ }^{13}$ lung cells, and cervical carcinoma cells $(\mathrm{HeLa})^{14}$ have been reported, HTLV-I is tropic for human lymphocytes, especially those with the CD4 surface phenotype. Our $\mathrm{T}$ cell line established from mononuclear cells of synovial fluid was positive for CD4 antigens and for activated or memory antigens, such as the IL-2 receptor, HLA-DR, and CD26 (Tal) antigens. The presence of CD29 and CD45RA antigens is an indication of different maturational status. ${ }^{15}$ CD45RA + cells are native cells that do not respond to recall antigens, whereas CD29+ cells are memory cells that have been activated by previous exposure to antigens. Although CD45RA and CD29 antigens are expressed reciprocally, the T cell line simultaneously expressed both CD45RA and CD29 antigens on the cell surface. Furthermore, the synovial fluid from our patient contained a higher percentage of CD4+CD29+ cells and a lower percentage of CD4+CD45RA+ cells than those of peripheral blood. Whether the double positive CD4+ cells in synovial fluid are preferentially infected by HTLV-I virus has yet to be determined.

Normal human lymphocytes have been shown to be transformed in vitro by HTLV-I when cocultured with HTLV-I producing T cells, and by this method the functions of HTLV-I infected T cell lines have been demonstrated. ${ }^{16} 17$ We therefore wished to determine the functions of an HTLV-I infected T cell line established from synovial fluid. T cell lines in vitro, transformed by HTLV-I, have been shown to produce such cytokines as IFN- $\gamma$, colony stimulating factor, macrophage activating factor, ${ }^{16}$ and IL-6. ${ }^{17}$ The T cells from the line used in our study secreted large amounts of IFN- $\gamma$, IL-6, and TNF- $\alpha$. It is apparent that these cytokines have a pivotal role in the perpetuation of the immune reaction in the synovial fluid of patients with rheumatoid arthritis. ${ }^{18}$ Because previous studies had shown that $T$ cells, transformed by HTLV-I, suppressed immunoglobulin production by B cells, although they expressed CD4 phenotypes, it was speculated that these $T$ cells might be suppressor-inducers. ${ }^{19}$ Our study, however, clearly showed that HTLV-I infected T cell lines secrete helper factors for the B cell responses; in particular, the $T$ cell line had the ability to enhance production of IgG by B cells. Our results are consistent with previous find- 
ings $^{20}$ that an HTLV-I infected peripheral blood $\mathrm{T}$ cell line assisted in $\mathrm{B}$ cell proliferation.

These findings raise the possibility that HTLV-I infected T cells infiltrating synovial tissues may produce cytokines, resulting in the triggering and perpetuation of immune responses in synovial tissue. A better understanding of HTLV-I associated rheumatic disorders should provide insights into the pathogenic mechanisms of these and other rheumatic diseases.

We thank Dr Yoshikatsu Hirai, Otsuka Pharmaceutical (Tokushima, Japan), for the detection of IL-6. The murine IL-6 dependent cell line, MH60.BSF-2, was kindly provided by Dr T Kishimoto (Osaka University, Japan).

1 Hinuma Y. A retrovirus associated with a human leukemia adult T-cell leukemia. Cur Top Microbiol Immunol 1985; adult $T$-cell

2 Osame M, Usuku K, Izumo S, et al. HTLV-I associated myelopathy; a new clinical study, Lancet 1986; i: 1031-2.

3 Nishioka K, Maruyama I, Sato K, Kitajima I, Nakajima Y Osame $M$. Chronic inflammatory arthropathy associated with HTLV-I. Lancet 1989; i: 441.

4 Ijichi S, Matsuda T, Maruyama I, et al. Arthritis in a human T lymphotrophic virus type I (HTLV-I) carrier. Ann Rheum Dis 1990; 49: 718-21.

5 Wiley C A, Nerenberg M, Ćros D, Soto-Aguilar M C. HTLV-I polymyositis in a patient also infected with the human immunodeficiency virus. $N$ Engl f Med 1989; 320: 992-5.

6 Eguchi K, Ueki Y, Shimomura C, et al. Increment in the Ta cells in the peripheral blood and thyroid tissue of patients with Graves' disease. F Immunol 1989; 142: 4233-40.

7 Nakamura T, Tsujihata M, Shirabe S, Matsuo H, Ueki Y, Nagataki S. Characterization of HTLV-I in a T cell line established from a patient with myelopathy. Arch Neurol 1989; 46: 35-7.
8 Matsuda $T$, Hirano $T$, Kishimoto $T$. Establishment of an interleukin 6 (IL-6)/B cell stimulating factor 2 -dependent cell line and preparation of anti-IL-6 monoclonal antibodies. Eur F Immunol 1988; 18: 951-6.

9 Ueki Y, Eguchi K, Fukuda T, et al. Dysfunction of suppressor $\mathrm{T}$ cells in thyroid glands from patients with Graves' disease. f Clin Endocrinol Metab 1987; 65: 922-8.

10 Taniguchi A, Takenaka Y, Noda Y, et al. Adult T cel leukemia presenting with proliferative synovitis. Arthritis Rheum 1988; 31: 1076-7

11 Kitajima I, Maruyama I, Maruyama Y, et al. Polyarthritis in human T lymphotropic virus type I-associated myelopathy. Arthritis Rheum 1989; 32: 1342-4.

12 Clapham P, Nagy K, Cheingsong-Popov R, Exley M, Weiss $R$ A. Productive infection and cell-free transmission of human $\mathrm{T}$-cell leukemia virus in a nonlymphoid cell line. Science 1983; 222: 1125-7.

13 Ho D D, Rota $T$, Hirsch M S. Infection of human endothelial cells by human T-lymphotropic virus type I. Proc Natl Acad Sci USA. 1984; 81: 7588-90.

14 Hayami M, Tsujimoto H, Komuro A, Hinuma Y, Fujiwara $\mathrm{K}$. Transmission of adult $\mathrm{T}$-cell leukemia virus from lymphoid cells to non-lymphoid cells associated with cell membrane fusion. Gann 1984; 75: 99-102.

15 Clement L T, Yamashita N, Martin A M. The functionally distinct subpopulations of human CD4+ helper/inducer T lymphocytes defined by anti-CD45R antibodies derive subsequentially from a differentiation pathway that is subsequentially from a differentiation pathway that is regulated by activation-dependent post-

16 Salahuddin S Z, Markham P D, Lindner S G, et al Lymphokine production by cultured human $T$ cells transformed by human T-cell leukemia-lymphoma virus-I. Science 1984; 223: 703-7.

17 Shimizu $\mathrm{K}$, Hirano $\mathrm{T}$, Ishibashi $\mathrm{K}$, et al. Immortalization of BGDF (BCGFII)- and BCDF-producing $T$ cells by human $T$ cell leukemia virus (HTLV) and characterization of T cell leukemia virus (HTLV) and characte

18 Emery P, Williamson D J, MacKay I R. Role of cytokines in rheumatological inflammation. Concepts Immunopathol 1987; 4: 171-9.

19 Hattori T, Uchiyama T, Toibana T, Takatsuki K, Uchino H. Surface phenotype of Japanese adult T-cell leukemia cells characterized by monoclonal antibodies. Blood 1981; 58: characteri

20 Ehrlich G D, Davey F R, Kirshner J J, et al. A polyclonal CD4+ and CD8+ lymphocytosis in a patient doubly infected with HTLV-I and HIV-1: a clinical and molecular analysis. Am f Hematol 1989; 30: 128-39. 